\title{
Mercury methylation in permafrost thaw ecosystems
}

\author{
J. CAnÁrio1*, M. Jusek1, H. Hintelmann2, M. Pilote3, G. \\ Hugelius4, J. Wagner4, G. Vieiras, V. Martin6, A. \\ RICHTER6, R. LODI7 AND H. LANTUIT8 \\ 1Centro de Química Estrutural, Universidade de Lisboa, \\ Lisboa, Portugal \\ (*correspondance; joao.canario@tecnico.ulisboa.pt) \\ 2Trent University, Peterborough, Canada \\ 3Environment and Climate Change Canada, Montreal, Canada \\ 4Stockholm University, Stockholm, Sweden \\ sIGOT, Universidade de Lisboa, Lisboa, Portugal \\ 6University of Vienna, Vienna, Austria \\ 7NRC, Institute of Polar Science, Venezia Mestre, Italy \\ 8Alfred-Wegener Institut, Helmholtz Centre for Polar and \\ Marine Research Potsdam, Germany
}

\section{Goal and Methods}

Arctic permafrost contains twice the amount of mercury (Hg) present in the world ocean, atmosphere and soils combined [1]. This $\mathrm{Hg}$ can potentially be remobilized during permafrost thaw, methylated and released to ecosystems. To identify and quantify $\mathrm{Hg}$ and methylmercury $(\mathrm{MeHg})$ levels and their transformation rates, permafrost soils, thaw lake waters and sediments were sampled in the Canadian Arctic and analyzed for $\mathrm{Hg}$ and $\mathrm{MeHg}$ content. Mercury methylation and $\mathrm{MeHg}$ demethylation rates were also calculated using $\mathrm{Hg}$ stable isotope techniques.

\section{Results and Discussion}

Concentrations of both $\mathrm{Hg}$ and $\mathrm{MeHg}$ were in generally low $(94 \pm 40 \mathrm{ngHg} / \mathrm{g} ; 1.4 \pm 1.0 \mathrm{ngMeHg} / \mathrm{g})$, however the proportion of $\mathrm{MeHg}$ to the total $\mathrm{Hg}$ content was well above the expected levels, particularly in permafrost soils collected in coastal areas (up to $3.2 \%$ ). Differences were also observed between samples from the active layer (up to $3.2 \%$ ) and from permafrost soils (up to $1 \%$ ), suggesting that the degradation of organic matter $(\mathrm{OM})$ is also performed by $\mathrm{Hg}$ methylating bacteria. In all samples $\mathrm{Hg}$ methylation rates were considerable higher (up to $1.2 \%$ ) than $\mathrm{MeHg}$ demethylation (up to $0.02 \%$ ) resulting in the observed $\mathrm{MeHg}$ accumulation. These rates were higher than the ones observed in contaminated sites [2] indicating that the conditions for transformation of inorganic $\mathrm{Hg}$ to $\mathrm{MeHg}$ is extremely efficient in thawing permafrost.

[1] Schuster et al. (2018) Geophys Res. Let. 45, 1463-1471.

[2] Cesário et al. (2017) Env. Poll. 226, 297-307. 